\title{
Targeting Mitochondrial Damage as a Therapeutic for Ileal Crohn's Disease
}

\author{
Kibrom M. Alula ${ }^{1}\left(\mathbb{D}\right.$, Dakota N. Jackson ${ }^{2}$, Andrew D. Smith ${ }^{3}$, Daniel S. Kim ${ }^{3}$, Kevin Turner 4,5, \\ Elizabeth Odstrcil ${ }^{2}$, Benny A. Kaipparettu ${ }^{6}$, Themistocles Dassopoulos ${ }^{2}$, K. Venuprasad ${ }^{4,5}$, Linda A. Feagins ${ }^{3,7}$ \\ and Arianne L. Theiss $1, * \mathbb{B}$
}

check for updates

Citation: Alula, K.M.; Jackson, D.N.; Smith, A.D.; Kim, D.S.; Turner, K.; Odstrcil, E.; Kaipparettu, B.A.; Dassopoulos, T.; Venuprasad, K.; Feagins, L.A.; et al. Targeting Mitochondrial Damage as a Therapeutic for Ileal Crohn's Disease. Cells 2021, 10, 1349. https://doi.org/ 10.3390/cells10061349

Academic Editor: David Sebastián

Received: 9 March 2021

Accepted: 27 May 2021

Published: 29 May 2021

Publisher's Note: MDPI stays neutral with regard to jurisdictional claims in published maps and institutional affiliations.

Copyright: (c) 2021 by the authors. Licensee MDPI, Basel, Switzerland. This article is an open access article distributed under the terms and conditions of the Creative Commons Attribution (CC BY) license (https:// creativecommons.org/licenses/by/ $4.0 /)$.
1 Division of Gastroenterology and Hepatology, University of Colorado School of Medicine, Aurora, CO 80045, USA; Kibrom.alula@cuanschutz.edu

2 Baylor University Medical Center, Department of Internal Medicine, Division of Gastroenterology, Baylor Scott \& White Research Institute, Dallas, TX 75246, USA; dnjackson12@gmail.com (D.N.J.); elizabethodstrcil@sbcglobal.net (E.O.); themistocles.dassopoulos@bswhealth.org (T.D.)

3 Department of Medicine, Veterans Affairs North Texas Health Care System, Dallas, TX 75216, USA; andrewdavidsmith88@gmail.com (A.D.S.); Daniel.kim1@va.gov (D.S.K.); Linda.Feagins@austin.utexas.edu (L.A.F.)

4 University of Texas Southern Medical Center, Department of Internal Medicine, College of Medicine, Dallas, TX 75390, USA; kevin.turner@informdx.com (K.T.); Venuprasad.Poojary@UTSouthwestern.edu (K.V.)

5 University of Texas Southern Medical Center, Department of Immunology, College of Medicine, Dallas, TX 75390, USA

6 Department of Molecular and Human Genetics, Baylor College of Medicine, Houston, TX 77030, USA; kaippare@bcm.edu

7 Department of Medicine, Dell Medical School, University of Texas at Austin, Austin, TX 78712, USA

* Correspondence: Arianne.theiss@cuanschutz.edu; Tel.: +1-303-724-7254

\begin{abstract}
Paneth cell defects in Crohn's disease (CD) patients (called the Type I phenotype) are associated with worse clinical outcomes. Recent studies have implicated mitochondrial dysfunction in Paneth cells as a mediator of ileitis in mice. We hypothesized that CD Paneth cells exhibit impaired mitochondrial health and that mitochondrial-targeted therapeutics may provide a novel strategy for ileal CD. Terminal ileal mucosal biopsies from adult CD and non-IBD patients were characterized for Paneth cell phenotyping and mitochondrial damage. To demonstrate the response of mitochondrial-targeted therapeutics in CD, biopsies were treated with vehicle or Mito-Tempo, a mitochondrial-targeted antioxidant, and RNA transcriptome was analyzed. During active CD inflammation, the epithelium exhibited mitochondrial damage evident in Paneth cells, goblet cells, and enterocytes. Independent of inflammation, Paneth cells in Type I CD patients exhibited mitochondrial damage. Mito-Tempo normalized the expression of interleukin (IL)-17/IL-23, lipid metabolism, and apoptotic gene signatures in CD patients to non-IBD levels. When stratified by Paneth cell phenotype, the global tissue response to Mito-Tempo in Type I patients was associated with innate immune, lipid metabolism, and G protein-coupled receptor (GPCR) gene signatures. Targeting impaired mitochondria as an underlying contributor to inflammation provides a novel treatment approach for CD.
\end{abstract}

Keywords: inflammatory bowel diseases; antioxidant; Type I Paneth cell phenotype; epithelial cells

\section{Introduction}

Crohn's disease (CD) is a type of inflammatory bowel disease (IBD) characterized by chronic relapsing intestinal inflammation involving the ileum in $~ 75 \%$ of patients [1]. Although the etiology of CD is unknown, it is thought to be a multifactorial condition resulting in heterogeneous disease across patients and presenting a challenge for therapeutic strategies. Several CD susceptibility genes integrate into cellular processes that converge on the homeostasis of Paneth cells, which are long-lived cells residing at the 
base of the small intestinal crypts interspersed between Lgr5-expressing intestinal stem cells (ISCs). Paneth cells produce and secrete antimicrobial peptides that are essential in epithelial defense and that shape the microbiota composition. Additionally, Paneth cells produce and secret important niche factors for neighboring ISCs, thereby promoting crypt homeostasis [2]. Previous studies have demonstrated that a subset of CD patients have Paneth cell defects (called Type I Paneth cell phenotype) and proposed that Paneth cell phenotyping can stratify CD patients by disease mechanism to enhance treatment outcomes [3]. Paneth cell abnormalities in CD patients are independent of inflammation, associated with early disease recurrence after resection, gut microbial dysbiosis, and decreased mucosal expression of genes that regulate oxidative phosphorylation, the latter suggesting that these patients may have mitochondrial alterations [3-8]. A recent study from our group implicated mitochondrial dysfunction specifically in Paneth cells as a mediator of spontaneous CD-like ileitis in mice [9].

Mitochondria are multifunctional organelles involved in energy production, reactive oxygen species (ROS) production, the induction of apoptosis, and control of intracellular calcium level. Additionally, mitochondria are important cellular signaling hubs, producing signaling intermediates in response to external stimuli. In the intestine, mitochondrial metabolism and function are involved in the activation of immune cells, maintenance of the epithelial barrier, and ISC homeostasis $[10,11]$. A series of studies have revealed the involvement of mitochondrial stress in IBD, with altered mitochondrial health implicated by both RISK (CD) and PROTECT (ulcerative colitis) pediatric gene expression studies [12,13]. Circulating mitochondrial DNA, a pro-inflammatory mediator, is released during active disease in $\mathrm{CD}$ and ulcerative colitis patients and can serve as a biomarker of disease severity [14]. Additionally, induction of the mitochondrial unfolded protein response has been demonstrated in the epithelial cells of CD and ulcerative colitis patients [15]. Overall, $5 \%$ of genes highlighted by IBD genome-wide association studies are functionally linked to the maintenance of mitochondrial health [16], further underpinning the role of deregulated mitochondrial function in IBD. In this prospective study, we sought to determine mitochondrial damage in the epithelium, including Paneth cells, during active and inactive disease and the transcriptomic response to mitochondrial therapeutic targeting in ileal CD.

\section{Materials and Methods}

\subsection{Patients}

A total of $50 \mathrm{CD}$ patients and 49 non-IBD controls were prospectively recruited from Baylor University Medical Center, Dallas, Texas and the Dallas Veterans Affairs Medical Center from April 2016 to August 2018. Non-IBD controls underwent an elective endoscopy for clinical purposes, did not have a history of IBD, and lacked endoscopic and histological inflammation. Biopsies were taken from the terminal ileum (from sites of endoscopically active and inactive disease if present for $\mathrm{CD}$ patients) using standard or jumbo forceps from the same site with the same endoscopic appearance to reduce heterogeneity across biopsies. During endoscopy, the degree of activity in the terminal ileum was scored using the Simple Endoscopic Score for Crohn's Disease (SES-CD), a validated endoscopic scoring system for mucosal inflammation [17]. A score of 0 identified inactive ileitis, and scores $\geq 1$ identified active ileitis [17]. Biopsies were immediately prepared in the endoscopy suite for downstream readouts: for electron microscopy, biopsies were placed in $2 \%$ glutaraldehyde solution and stored at $4{ }^{\circ} \mathrm{C}$ until being processed; for immunofluorescent staining, biopsies were embedded in OCT and immediately frozen; for ex vivo Mito-Tempo treatment, biopsies were placed in culture media on ice. To test the role of dampened mtROS signaling in active disease, only active $\mathrm{CD}$ biopsies were treated with Mito-Tempo and processed for global RNA sequencing (RNA-seq). 
2.2. Paneth Cell Phenotype Analysis_Immunofluorescent Staining of Lysozyme and Quantitation of Lysozyme Granule Allocation Pattern

OCT-embedded biopsies were sectioned and incubated with lysozyme antibody (W20, sc-27956, Santa Cruz Biotechnology, Dallas (TX), USA) at 1:75 dilution followed by secondary antibody Rhodamine Red ${ }^{\mathrm{TM}}-\mathrm{X}$ (RRX) AffiniPure Donkey Anti-Goat IgG (711296-152, Jackson Immuno, West Grove (PA), USA) at 1:500 dilution. Sections were then stained with 4',6-diamidino-2-phenylindole dihydrochloride (DAPI, D9542, Sigma Aldrich, St Louis (MO), USA) at 1:1000 for $5 \mathrm{~min}$. For Paneth cell phenotyping classification, only samples with an adequate number of crypts $(\geq 40)$ were included, as previously described [5]. Each Paneth cell was observed in a blind fashion for disease status for lysozyme granule allocation pattern as previously described $[3-6,18,19]$. Briefly, each Paneth cell was classified into the following categories: normal, disordered (abnormal distribution and size of granules), diminished ( $\leq 10$ granules), diffuse (no recognizable granules), excluded (majority of granules do not contain lysozyme stain), or enlarged (lower number of megagranules) [19]. The percentage of abnormal Paneth cells within each sample was calculated to define the Paneth cell phenotype as previously described; the Type I Paneth cell phenotype was defined as $\geq 20 \%$ of total Paneth cells demonstrating abnormal lysozyme granule allocation patterns and the Type II Paneth cell phenotype was defined as $<20 \%$ of total Paneth cells demonstrating abnormal lysozyme granule allocation patterns $[3-6,18,19]$.

\subsection{Transmission Electron Microscopy (TEM)}

Biopsies were fixed in $2 \%$ glutaraldehyde in $1 \times$ PBS, dehydrated and embedded in epoxy resin for electron microscopy. Ultrathin $70 \mathrm{~nm}$ sections were examined on a transmission electron microscope (TEM) (Hitachi BioMedical, Twinsburg, OH, USA). For each patient, we observed mitochondria in 3 different cell types: Paneth cells, goblet cells, and enterocytes. Each mitochondrion was observed in a blind fashion and classified as having normal or abnormal ultrastructural features (altered morphological features including dissolved cristae and electron-dense inclusion bodies). Per patient, an average of 320 mitochondria in Paneth cells were quantitated ( $20 \pm 0.5$ Paneth cells per patient with an average of 16 mitochondria per Paneth cell). An average of 300 mitochondria in goblet cells were quantitated ( 20 goblet cells per patient with an average of $15 \pm 0.8$ mitochondria per goblet cell) and an average of 1520 mitochondria in enterocytes were quantitated (40 enterocytes per patient with an average of $38 \pm 0.6$ mitochondria per enterocyte). In Paneth cells, individual mitochondria were analyzed for the following morphological features: perimeter $(\mathrm{nm})$ by manual tracing in ImageJ software, circularity $\left(4 \pi\left(\right.\right.$ area $/$ perimeter $\left.{ }^{2}\right)$, number of cristae, and number of electron-dense inclusion bodies.

\subsection{Risk Allele Analysis}

The presence of single nucleotide polymorphisms (SNPs) for ATG16L1 (rs2241880), and NOD2 (rs2066844, rs2066845, rs2066847) was identified during RNA-seq analysis (Novogene, Beijing, China) that involved alignment (picard tools v1.111 and samtools v0.1.18), calling SNP (HaplotypeCaller GATK4.1 version), and SNP annotation (annovar) against dbSNP and other databases.

For patients who were only able to provide inactive disease biopsies (which were excluded from RNA-seq analysis since only active biopsies were analyzed), ATG16L1 (rs2241880) was genotyped by Sanger sequencing. Genomic DNA was isolated from patient biopsies using AllPrep DNA/RNA kit (69504, Qiagen, Hilden, Germany). Genomic DNA for ATG16L1 was amplified by PCR with Platinum Taq DNA Polymerase High Fidelity (11304-011, Invitrogen, Carlsbad, CA, USA), dNTP Mix, PCR Grade (201900, Qiagen), and the following primers from Invitrogen: forward: $5^{\prime}$-ACAGGTTAGTGTGCAGGAGA-3' and reverse: $5^{\prime}$-CAGTCAGCTCTGCCATTACA-3. PCR conditions: $95^{\circ} \mathrm{C} 2 \mathrm{~min}, 33$ cycles, $95{ }^{\circ} \mathrm{C} 30 \mathrm{~s}, 53{ }^{\circ} \mathrm{C} 20 \mathrm{~s}, 72{ }^{\circ} \mathrm{C} 30 \mathrm{~s}$. The amplified product was purified using QIAquick PCR 
Purification Kit (28104, Qiagen). Sanger sequencing was conducted by Eurofins using the following sequencing primer: 5'-TGCAGGAGAGTAAGGCATGT-3'.

\subsection{Ex Vivo Mito-Tempo Treatment}

Biopsies obtained from active sites of $\mathrm{CD}$ and non-IBD control biopsies were placed in $300 \mu \mathrm{L}$ DMEM culture media in the endoscopy suite and placed on ice. Within $30 \mathrm{~min}$, the biopsies were transported to the lab, dabbed to remove excess culture media, and weighed. Biopsies were then incubated in $300 \mu \mathrm{L}$ DMEM culture media containing $40 \mathrm{mg} / \mathrm{L}$ penicillin, $90 \mathrm{mg} / \mathrm{L}$ streptomycin, and $0.5 \mu \mathrm{g} / \mathrm{g}$ tissue Mito-Tempo or vehicle; two biopsies from each patient were used, one biopsy treated with Mito-Tempo and one with vehicle. Biopsies were cultured in a humidified environment at $37^{\circ} \mathrm{C}$ and $5 \% \mathrm{CO}_{2}$ for $2 \mathrm{~h}$ then moved from the culture media and incubated in RNAlater (Qiagen).

\subsection{Global RNA Sequencing (RNA-Seq)}

Total RNA was isolated from patient biopsies using AllPrep DNA/RNA kit (69504, Qiagen). Samples were sent to Novogene for RNA sequencing. Of the active biopsies from 19 CD patients, 16 treated with Mito-Tempo and 13 treated with vehicle had transcriptome data that passed quality control and library construction (Figure 1 ). Of the remaining 25 nonIBD patients, 15 biopsies treated with Mito-Tempo and 13 biopsies treated with vehicle had transcriptome data that passed quality control and library construction. Alignments were parsed using the STAR program and differential expressions were determined through DESeq2/edgeR. GO and KEGG enrichment were implemented by the ClusterProfiler. Reference genome and gene model annotation files were downloaded from genome website browser (NCBI/UCSC/Ensembl) directly. Indexes of the reference genome was built using STAR and paired-end clean reads were aligned to the reference genome using STAR (v2.6.1). STAR used the method of maximal mappable prefix (MMP), which can generate a precise mapping result for junction reads. STAR counted the number of reads per gene while mapping. The counts coincide with those produced by htseq-count with default parameters. Then, the FPKM of each gene was calculated based on the length of the gene and reads count mapped to this gene. Differential expression analysis between two groups was performed using the DESeq2 R package (1.14.1). IDEP.91, a web-based program (http:/ / bioinformatics.sdstate.edu/idep/, accessed on 15 March 2021) was used to further analyze and identify pathways related to up- and downregulated gene expression as a result of Mito-TEMPO treatment of CD patients by Reactome enrichment pathway analysis of differentially expressed genes. Heatmaps were generated using the web-based program called Heatmapper (http:/ / www.heatmapper.ca/expression/, accessed on 15 March 2021).

\subsection{Quantitative Real-Time PCR Analysis}

For graphical representation of quantitative PCR data, the $\Delta \Delta C_{T}$ was calculated as follows: $\Delta \Delta \mathrm{C}_{\mathrm{T}}=\left(\mathrm{Ct}\right.$, target $-\mathrm{Ct}$, $\left.{ }_{18 \mathrm{~S}}\right)$ all other treatment groups $-(\mathrm{Ct}$, target $-\mathrm{Ct}$, 18S $)$ non-IBD veh, with the final graphical data derived from $2^{-\triangle \Delta C T}$. Primers from Integrated DNA Technologies: FAS forward: 5'-GTGATGAAGGACATGGCTTAGA-3' and FAS reverse: $5^{\prime}-$ GGGTCACAGTGTTCACATACA-3. ACADS forward: 5'-CATCTACCAGTCTGTGGAAC TG-3' and ACADS reverse: $5^{\prime}$-GCTGGGAAGAGATGTTCCTTAT-3. FAAH forward: $5^{\prime}-$ GGTGCAGAAGTTACACAGTAGAG- $3^{\prime}$ and FAAH reverse: $5^{\prime}$-AGTCTCACAGTCAGCCA GATA-3. IL17F forward: $5^{\prime}$-TGTGCCAGGAGGTAGTATGA-3' and IL17F reverse: $5^{\prime}-$ GGTCCCAAGTGACAGTGTAAT-3. IL23A forward: $5^{\prime}$-GGGACACATGGATCTAAGAG AAG-3' ${ }^{\prime}$ and IL23A reverse: $5^{\prime}$-TGCAAGCAGAACTGACTGT-3. 18 S forward: $5^{\prime}$-CCCCTCG ATGCTCTTAGCTGAGTG-3' and $18 \mathrm{~S}$ reverse: $5^{\prime}$-CGCCGGTCCAAGAATTTCACCTCT-3. 
A
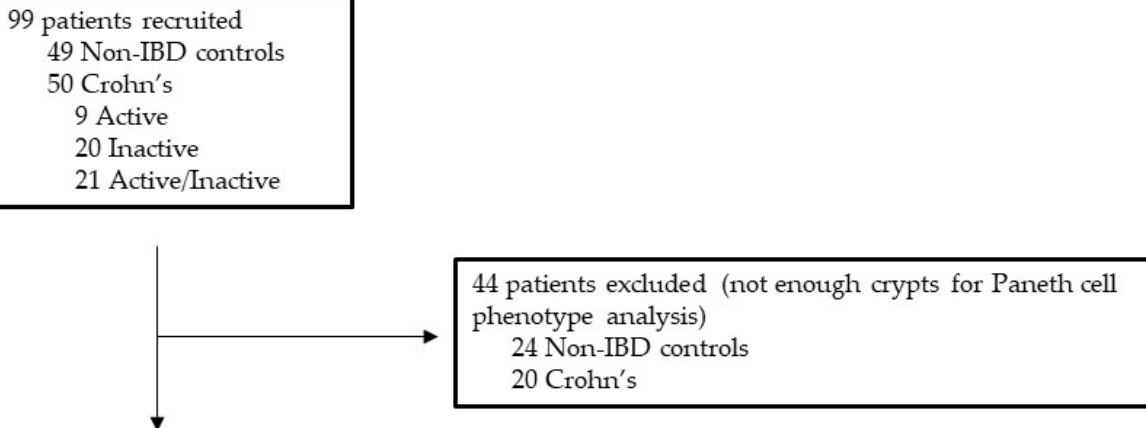

55 patients with Paneth cell phenotype analysis

25 Non-IBD controls

25 with EM

13 veh, 15 mito-Tempo with RNA

25 with DNA

30 Crohn's

11 Inactive

11 with EM

11 with DNA

19 Active/Inactive

19 inactive with EM, 19 active with EM

13 active veh, 16 active mito-Tempo with RNA

19 with DNA

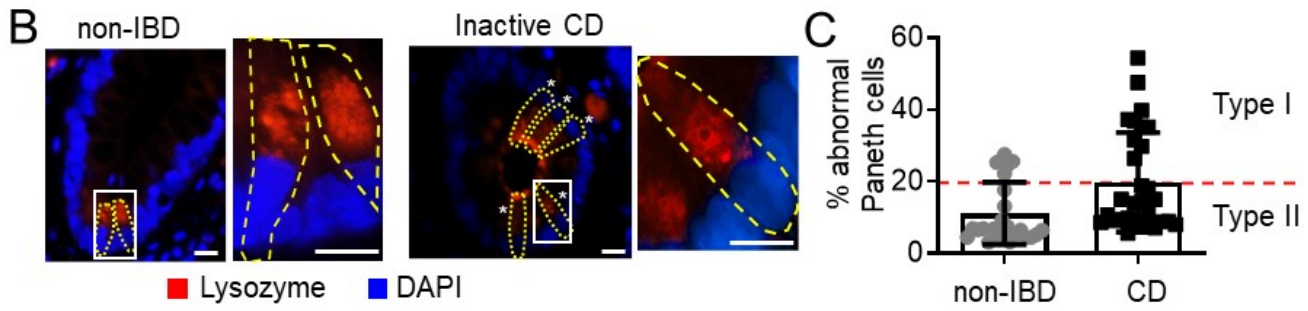

Figure 1. Flowchart of recruited and excluded patients and Type I Paneth cell phenotyping. (A) Number of patients recruited into analysis for Paneth cell phenotyping, EM, RNA-seq, and presence of autophagy-related SNPs. (B) Example of lysozyme immunofluorescent staining for Paneth cell (yellow outline) phenotype analysis. Star denotes abnormal lysozyme allocation pattern. Box denotes area of higher magnification. Scale bars: $10 \mu \mathrm{m}$. (C) \% abnormal Paneth cells. A minimum of 40 well-oriented crypts were quantitated for each patient.

\subsection{Statistics}

Data represent individual data points \pm SEM. For patient demographics, a nonparametric Mann-Whitney-Wilcoxon test was used for continuous variables and a chisquare/Fisher's exact test was used for associations between characteristics. Spearman rank was used to calculate the association between $\%$ of abnormal Paneth cells and $\%$ of Paneth cells with unhealthy mitochondria. An unpaired two-tailed $t$ test was performed for the comparison of means between two groups. Multiple comparisons were conducted with either one-way or two-way ANOVA followed by a Bonferroni post hoc test (GraphPad Prism 8.4.2, San Diego, CA, USA). For transcriptome analysis, differential expression analysis between two groups was performed using the DESeq2 R package (1.14.1). The resulting $p$-values were adjusted using Benjamini and Hochberg's approach for controlling the false discovery rate (FDR). Genes with an adjusted $p$-value $<0.05$ found by DESeq2 were assigned as differentially expressed. Reactome terms with a $p$-value $<0.05$ were considered significantly enriched by differential expressed genes. 


\section{Results}

3.1. Mitochondria Exhibit Damage in Paneth Cells, Goblet Cells, and Enterocytes during Active $C D$ and in Paneth Cells of Type I CD Patients Independent of Inflammation

A novel cohort of patients was recruited from two centers in Dallas, TX to investigate mitochondrial health in Paneth cells of the terminal ileum (Table 1). Non-IBD control subjects were significantly older than CD patients $(p=0.0002$, Mann-Whitney-Wilcoxon test). No differences were noted between $\mathrm{CD}$ and non-IBD patients with regard to gender, race, reported smoking status, or co-morbidities. After Paneth cell phenotype analysis, $20 \mathrm{CD}$ patients and 24 non-IBD patients were excluded as the biopsy samples had an inadequate number of crypts ( $<40$ artifact-free crypts [5]) for Paneth cell phenotyping (Figure 1A). The prevalence of the Type I Paneth cell phenotype in our cohort was 33\% (10 of 30) for CD patients and 24\% (6 of 25) for non-IBD patients (Figure 1B,C), which agrees with previous studies demonstrating that the Type I Paneth cell phenotype occurs in $\sim 25 \%$ of adult CD patients and is independent of active inflammation [5]. Since CD genetic susceptibility variants in ATG16L1 T300A or NOD2 genes are associated with Paneth cell defects in other cohorts of patients [3,4], we next determine whether these genetic variants are present in our CD cohort. The ATG16L1 T300A variant was found in 63\% (19 of 30) of CD patients and correlated with the Type I Paneth cell phenotype ( $p=0.048$, chi-square/Fisher's exact test) as previously published. The NOD2 risk SNPs were not present in this cohort of $\mathrm{CD}$ patients.

Table 1. Characteristics of patients recruited into analysis.

\begin{tabular}{|c|c|c|c|}
\hline Characteristic & $\begin{array}{l}\text { Non-IBD } \\
\text { Control }\end{array}$ & CD & $\begin{array}{c}p \text {-Value CD vs. } \\
\text { Non-IBD }\end{array}$ \\
\hline Number of patients & 25 & 30 & \\
\hline \multicolumn{4}{|l|}{ Gender, $n(\%)$} \\
\hline Male & $11(44)$ & $19(63)$ & 0.11 \\
\hline Female & $14(56)$ & $11(37)$ & \\
\hline Median age (range) & $61(25-80)$ & $49(20-71)$ & 0.0002 \\
\hline \multicolumn{4}{|l|}{ Race, $n(\%)$} \\
\hline Caucasian & $17(68)$ & $24(80)$ & 0.36 \\
\hline African American & $8(32)$ & $3(10)$ & 0.09 \\
\hline Asian & 0 & $1(3)$ & 0.99 \\
\hline Hispanic & 0 & $2(6)$ & 0.50 \\
\hline Harvey Bradshaw Index Score & $\mathrm{N} / \mathrm{A}$ & $0-22$ & \\
\hline \multicolumn{4}{|l|}{ IBD treatment at biopsy, $n(\%)$} \\
\hline 5-ASA & & $5(17)$ & \\
\hline 6-MP/AZA/MTX & & $6(20)$ & \\
\hline Biologics a & & $17(56)$ & \\
\hline Steroids & & $6(20)$ & \\
\hline Antibiotics & & 0 & \\
\hline NSAIDS & & $4(13)$ & \\
\hline No treatment & & $5(17)$ & \\
\hline \multicolumn{4}{|l|}{ Tobacco use ${ }^{\mathrm{b}}, n(\%)$} \\
\hline Smoker & $1(4)$ & $3(10)$ & 0.99 \\
\hline Non-smoker & $17(68)$ & $26(87)$ & 0.07 \\
\hline \multicolumn{4}{|l|}{ Other conditions, $n(\%)$} \\
\hline Coronary artery disease & $2(8)$ & $1(3)$ & 0.59 \\
\hline Diabetes mellitus & $3(12)$ & $4(13)$ & 0.99 \\
\hline Hypertension & $10(40)$ & $9(30)$ & 0.78 \\
\hline COPD & $1(4)$ & 0 & 0.45 \\
\hline Congestive heart failure & $2(8)$ & $1(3)$ & 0.59 \\
\hline
\end{tabular}


Table 1. Cont.

\begin{tabular}{cccc}
\hline Characteristic & $\begin{array}{c}\text { Non-IBD } \\
\text { Control }\end{array}$ & CD & $\begin{array}{c}p \text {-Value CD vs. } \\
\text { Non-IBD }\end{array}$ \\
\hline Cerebrovascular event & 0 & $3(10)$ & 0.24 \\
Peripheral vascular dis. & $1(4)$ & 0 & 0.45 \\
Ankylosing spondylitis & 0 & $4(13)$ & 0.12 \\
Rheumatoid Arthritis & $2(8)$ & $1(3)$ & 0.59 \\
Psoriasis & 0 & $1(3)$ & 0.99 \\
Spondyloarthropathy & 0 & $2(7)$ & 0.49 \\
\hline
\end{tabular}

a Infliximab, adalimumab, vedolizumab, ustekinimab. ${ }^{\mathrm{b}}$ Missing data from 7 non-IBD and $1 \mathrm{CD}$ patients. CD, Crohn's disease; 5-ASA, 5-aminosalicylic acid; 6-MP, 6-mercaptopurin; AZA, Azathioprine; MTX, Methotrexate; NSAIDs, nonsteroidal anti-inflammatory drugs; COPD, chronic obstructive pulmonary disease.

Specimens were processed for transmission electron microscopy (TEM) to visualize mitochondrial morphology. Quantitative measurements of mitochondria demonstrated a decreased perimeter and number of cristae and increased circularity and number of dense bodies in CD Paneth cell mitochondria compared to non-IBD controls, with the most severe changes in active CD (Figure 2A,B). In Paneth cells, ultrastructural abnormalities in mitochondria (dissolved cristae, electron-dense inclusion bodies) were demonstrated in an average of $9.2 \%$ of mitochondria of non-IBD patients, $20.3 \%$ of mitochondria of inactive CD patients, and $73.3 \%$ of mitochondria of active CD patients (Figure $2 \mathrm{C}$ ). These results suggest that $\mathrm{CD}$ biopsies taken from sites of active disease exhibited a high proportion of Paneth cells with mitochondrial abnormalities, likely due to inflammatory damage, as has been shown previously [11]. Interestingly, inactive CD Paneth cells exhibited a range of mitochondrial ultrastructural abnormalities, with some patients exhibiting a normal mitochondrial pool reflecting that of non-IBD, and other patients exhibiting a larger portion of mitochondria with abnormalities (Figure 2C). The highest percentage of Paneth cells with mitochondrial abnormalities stratified as Type I Paneth cell phenotype in inactive CD and non-IBD biopsies (Figure 2D). This did not correlate in active CD biopsies, likely due to inflammation as a confounding factor (Figure 2D). These results suggest that Paneth cell defects are associated with mitochondrial ultrastructural alterations independent of inflammation.

Further examination of other epithelial cell types including enterocytes and goblet cells revealed increased mitochondrial ultrastructural abnormalities during active $C D$ in these cell types (Figure 3). In inactive CD sites, enterocytes and goblet cells exhibited a low proportion of mitochondrial abnormalities in contrast to Paneth cells. Those inactive CD patients with the percentage of abnormal mitochondria above the mean $(20.3 \%$; Figure 2C) will be referred to as the abnormal Paneth cell mitochondrial phenotype herein. Of the 30 CD patients, 11 fit the classification of abnormal PC mitochondrial phenotype, which was significantly associated with the Type I Paneth cell phenotype $(p<0.0001$, chi-square/Fisher's exact test; Table 2). No differences were noted between the normal and abnormal Paneth cell mitochondrial phenotypes in regard to gender, age, race, disease severity (Harvey Bradshaw Index Score or the presence of endoscopic active inflammation), treatment at biopsy, smoking status, or co-morbidities (Table 2).

3.2. Mito-Tempo, a Mitochondrial-Targeted Therapeutic, Restores Altered CD Genes Involved in Immune Response, Apoptotic, and Metabolism Pathways to Non-IBD Expression Levels

Given emerging studies suggesting mitochondrial dysfunction in $\operatorname{IBD}[9,20]$ and our results demonstrating that $\mathrm{CD}$ biopsies taken from sites of active disease exhibited a high proportion of Paneth cells, goblet cells, and enterocytes with mitochondrial abnormalities, targeting impaired mitochondria as an underlying contributor to inflammation could provide a novel treatment approach for CD. Increased ROS derived from damaged mitochondria are a key source of cellular and tissue damage [21]. Mito-Tempo is a mitochondrial-targeted superoxide dismutase 2 (SOD2) mimetic shown to have antioxidant properties and to ameliorate ileitis in mice driven by mitochondrial dysfunction $[9,22]$. To 
demonstrate the response of mitochondrial-targeted therapeutics in $\mathrm{CD}$, transcriptomic analysis of active $\mathrm{CD}$ biopsies treated with Mito-Tempo is an unbiased approach to assess inflammatory and other pathological pathways. Active CD biopsies and non-IBD control biopsies were incubated for $2 \mathrm{~h}$ in culture media containing $0.5 \mu \mathrm{g} / \mathrm{g}$ tissue Mito-Tempo or vehicle. This time point was chosen since it is prior to epithelial cell death [23] but allows ample transcriptomic changes which were measured by global RNA sequencing (RNA-seq).

A
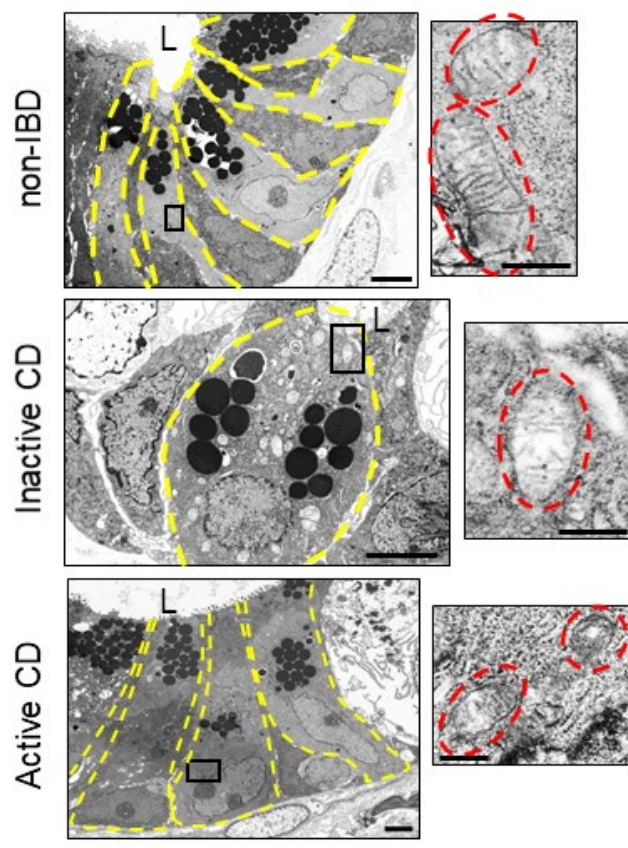

$\mathrm{D}$

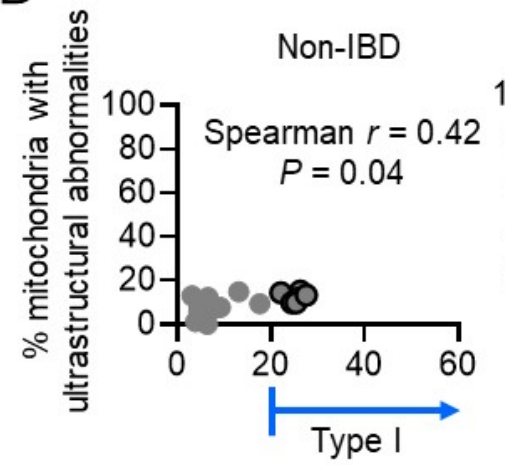

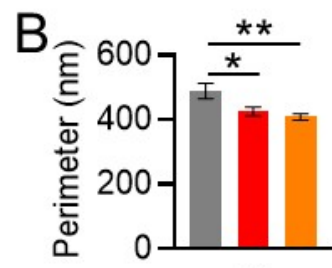
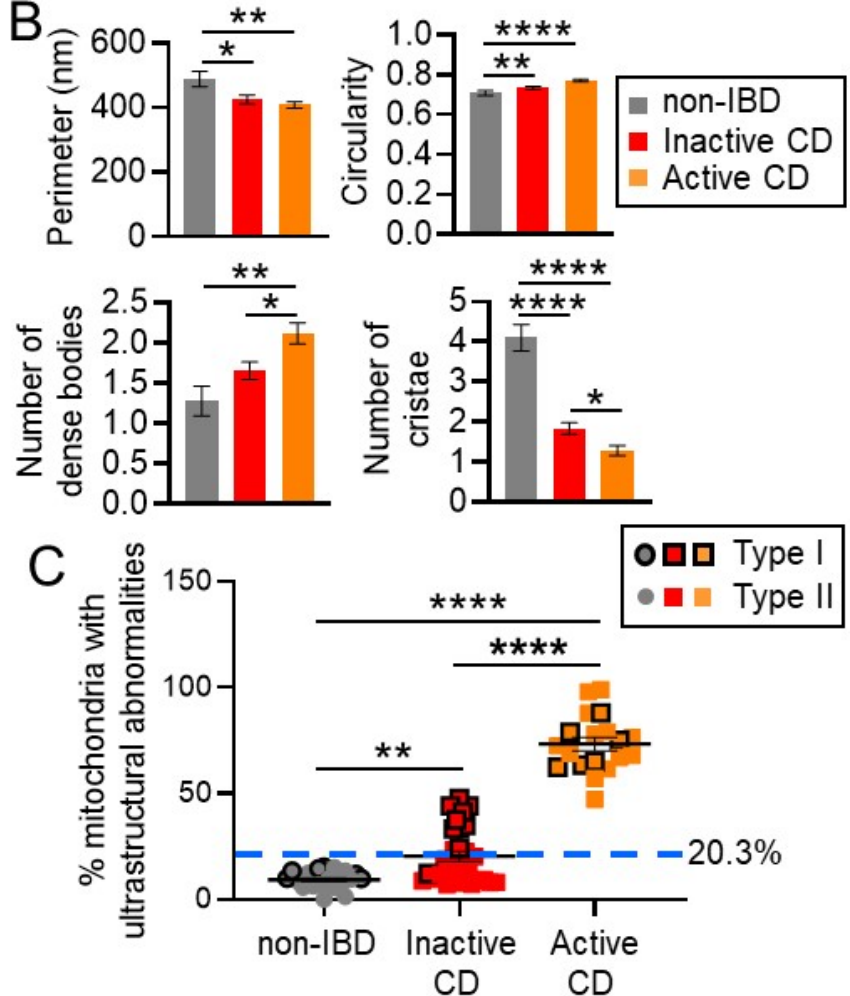

$\%$ Paneth cells with abnormal lysozyme

Figure 2. Ileal CD patients with unhealthy mitochondria stratify as Type I abnormal Paneth cell phenotype. (A) Representative TEM image of Paneth cell (yellow outline) mitochondria (red outline). Scale bars: $4 \mu \mathrm{m}$, boxed pullout: $500 \mathrm{~nm}$. L, lumen. (B) Quantitation of mitochondrial parameters in Paneth cells measured by ImageJ fromTEM images. (C) Quantitation of \% Paneth cell mitochondria per patient with ultrastructural abnormalities (dissolved cristae, electron-dense inclusion bodies). (D) Spearman's rank correlation. Results are presented as individual data points \pm SEM of 25 non-IBD and 30 inactive CD patients. ${ }^{*} p<0.05,{ }^{* *} p<0.01,{ }^{* * * *} p<0.001$ by one-way ANOVA and Tukey's post hoc test. 

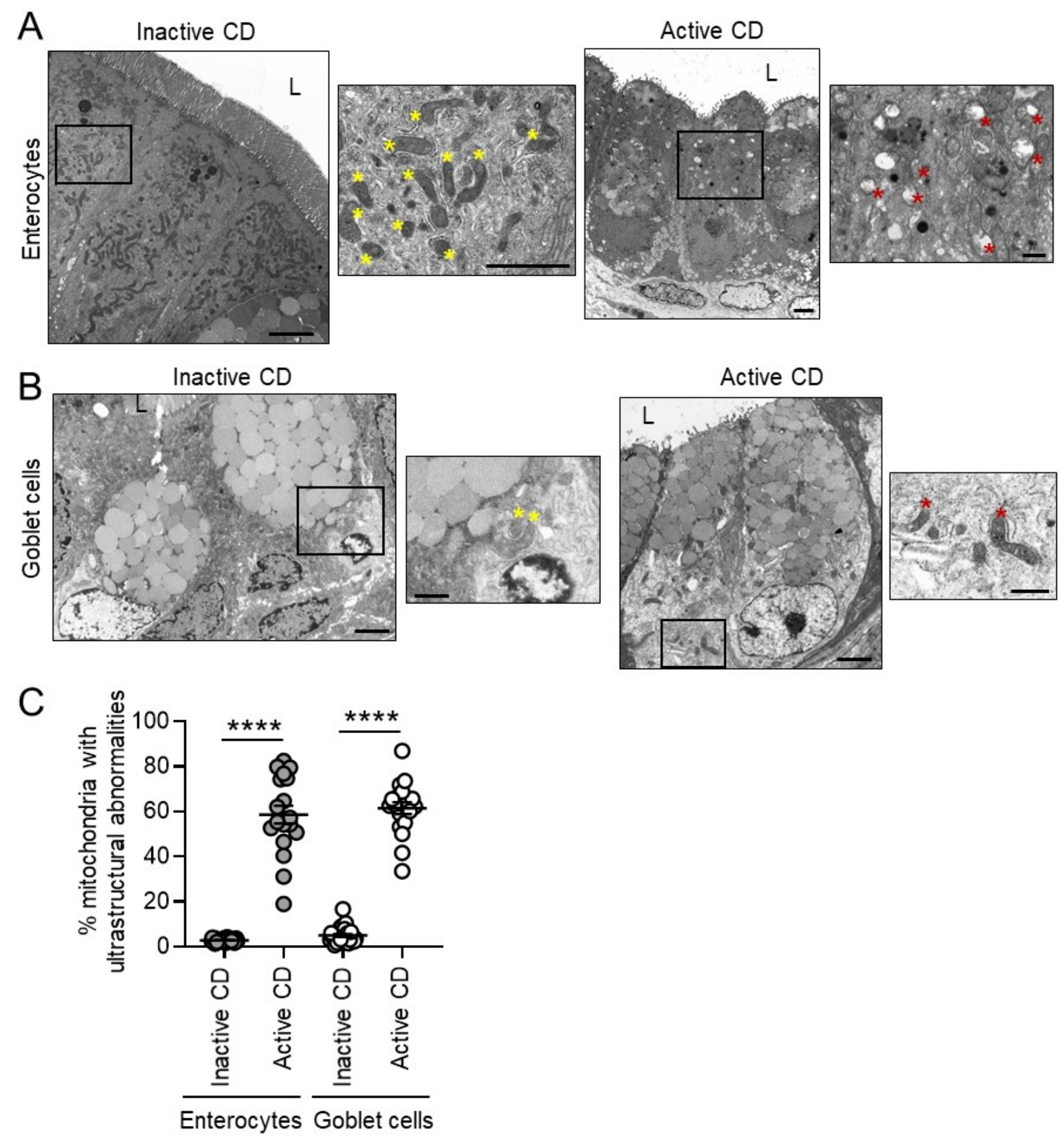

Figure 3. Active $C D$ is associated with mitochondrial ultrastructural abnormalities in enterocytes and goblet cells. (A,B) Representative TEM image of enterocytes (A) and goblet cells (B). Yellow star denotes normal mitochondria, red star mitochondria with ultrastructural abnormality. Scale bars: $2 \mu \mathrm{m}$, boxed pullout: $1 \mu \mathrm{m}$. (C) Quantitation of mitochondria with ultrastructural abnormalities. Results are presented as individual data points \pm SEM of 30 inactive and 19 active CD patients. ${ }^{* * * *} p<0.001$ by one-way ANOVA and Bonferroni post hoc test $(\mathbf{C})$. 
Table 2. Charcteristics of CD patients classified as Paneth cell abnormal mitochondria phenotype.

\begin{tabular}{|c|c|c|c|}
\hline Characteristic & $\begin{array}{c}\text { Normal } \\
\text { Mitochondria }\end{array}$ & $\begin{array}{c}\text { Abnormal } \\
\text { Mitochondria }\end{array}$ & $\begin{array}{c}p \text {-Value Normal vs. } \\
\text { Abnormal } \\
\text { Mitochondria }\end{array}$ \\
\hline Number of patients & 19 & 11 & \\
\hline \multicolumn{4}{|l|}{ Gender, n (\%) } \\
\hline Male & $14(74)$ & $6(54)$ & 0.24 \\
\hline Female & $5(26)$ & $5(46)$ & \\
\hline \multicolumn{4}{|l|}{ Age, $\mathrm{n}(\%)$} \\
\hline$<40$ & $8(42)$ & $3(27)$ & 0.47 \\
\hline$<50$ & $10(53)$ & $6(54)$ & 0.99 \\
\hline$<60$ & $14(74)$ & $8(72)$ & 0.99 \\
\hline \multicolumn{4}{|l|}{ Race, $\mathrm{n}(\%)$} \\
\hline Caucasian & $16(84)$ & $8(72)$ & 0.64 \\
\hline African American & $2(11)$ & $1(9)$ & 0.99 \\
\hline Asian & 0 & $1(9)$ & 0.37 \\
\hline Hispanic & $1(5)$ & $1(9)$ & 0.99 \\
\hline \multicolumn{4}{|l|}{ Harvey Bradshaw Index Score, n (\%) } \\
\hline$<5$ & $11(58)$ & $9(82)$ & 0.25 \\
\hline 5 to 7 & $5(26)$ & $2(18)$ & 0.99 \\
\hline 8 to 16 & $1(5)$ & 0 & 0.99 \\
\hline$>16$ & $1(5)$ & 0 & 0.99 \\
\hline $\begin{array}{c}\text { Endoscopically active disease } \\
\text { present, } \mathrm{n}(\%)\end{array}$ & $11(58)$ & $5(46)$ & 0.71 \\
\hline \multicolumn{4}{|l|}{ IBD treatment at biopsy, $\mathrm{n}(\%)$} \\
\hline 5-ASA & $3(16)$ & $2(18)$ & 0.99 \\
\hline 6MP/AZA/MTX & $4(21)$ & $2(18)$ & 0.99 \\
\hline Biologics & $10(53)$ & $7(64)$ & 0.71 \\
\hline Steroids & $2(11)$ & $4(36)$ & 0.16 \\
\hline NSAIDS & $1(5)$ & $3(27)$ & 0.13 \\
\hline No treatment & $3(16)$ & $2(18)$ & 0.99 \\
\hline Smoking, n (\%) & $1(5)$ & $2(18)$ & 0.54 \\
\hline Type I Paneth cell phenotype, n (\%) & $1(5)$ & $9(82)$ & $<0.0001$ \\
\hline \multicolumn{4}{|l|}{ Other conditions, $\mathrm{n}(\%)^{\text {a }}$} \\
\hline Diabetes mellitus & $1(5)$ & $3(27)$ & 0.13 \\
\hline Hypertension & $4(21)$ & $5(46)$ & 0.23 \\
\hline Cerebrovascular event & $1(5)$ & $2(18)$ & 0.54 \\
\hline Ankylosing spondylitis & $2(11)$ & $2(18)$ & 0.61 \\
\hline
\end{tabular}

a Too few patients for analysis for conditions not listed.

Compared to non-IBD controls (non-IBD vehicle), there were 1232 upregulated differentially expressed genes (DEGs) and 1065 downregulated DEGs in CD patients (CD vehicle) (Figure 4A,B, Table S1). These altered DEGs in CD patients associated with gene signature pathways including metabolism, signal transduction, autophagy, and antimicrobial peptides (Figure S1). Of the 1232 upregulated genes in CD patients, 253 were restored to the non-IBD expression level by Mito-Tempo (Figure 4A and Table S2). Of the 1065 downregulated genes in CD patients, 325 were restored to the non-IBD expression level by Mito-Tempo (Figure 4B and Table S3). Therefore, Mito-Tempo normalized 25\% of altered genes in active CD biopsies after only $2 \mathrm{~h}$. The effect of Mito-Tempo on these genes in non-IBD patients (non-IBD Mito-Tempo vs. non-IBD vehicle) was minor compared to its effect in CD patients (Figure 4A,B). The Mito-Tempo-restored genes in CD included signatures associated with the cell cycle (specifically mitosis), innate immune system, apoptotic, and metabolism pathways (Figure 4C). Numerous genes in the interleukin (IL)17/IL-23 signaling pathway were altered in CD biopsies and normalized by Mito-Tempo treatment (IL23A, IL17F, IL32, IL17RC, CCL22, CCL17, IRF4, PGLYRP1) (Figure 4D). The IL-17/IL-23 pathway plays a central role in mediating intestinal inflammation by controlling activation of Th1 and Th17 cells and dampening Treg cell expansion [24]. Additionally, in CD biopsies, Mito-Tempo decreased expression of antigen processing genes (IF130, 
TNFRSF17, IGHG3, IGKVs, IGLVs, IGHVs) and pro-apoptotic genes (FAS, PMAIP1, BBC3) (Figure 4D). Multiple immune response genes that are downregulated in $\mathrm{CD}$ and restored by Mito-Tempo are protective against intestinal inflammation (SMURF2, CD160, MT1A, MT2A, SI, DEFB1) [25-28] and promote epithelial barrier function (CLDN8, CLDN15, DLG1) (Figure 4D) [29-31]. Additionally, three of the six Reactome pathways under "Metabolism" (Figure 4C) specifically involved lipid metabolism with multiple lipid metabolism genes downregulated in $\mathrm{CD}$, as previously reported [32], and normalized by Mito-Tempo treatment (HADHB, HADH, ACADS, ACOT12, ACOX1, ECI2, FAAH). Relative change in the expression of representative genes FAS (apoptosis), FAAH, ACADS (lipid metabolism), Il23A, Il17F, was similar to expression patterns demonstrated by RNAseq analysis (Figure S2). Mitochondrial biogenesis gene PPARGC1A was upregulated during CD and not significantly altered by Mito-Tempo (Figure S2). Collectively, these results suggest that Mito-Tempo exhibits therapeutic potential to normalize the expression of these $C D$ disease pathways to levels demonstrated in non-IBD patients.

\subsection{Paneth Cell Phenotype Is Associated with Unique Mito-Tempo-Induced Gene Signatures}

Although Mito-Tempo likely affects numerous cell types in the whole tissue, global response to Mito-Tempo may be associated with the Paneth cell subtype of CD. Transcriptomics of Mito-Tempo treatment was stratified based on CD patient Paneth cell phenotyping as Type I or Type II. 376 genes were differentially expressed between Type I and Type II CD specimens ( $p$ adj. $<0.06, p<0.05$; Figure 5A; Table S4). Mito-Tempoaltered genes in Type I CD associated with innate immune response (SIGLEC14, SIGLEC5, DEFB124, FCN3, CHI3L1, IGHV1-69, IGHV3-7, IGHV4-34, IGHV10-54, IGHG3) and lipid metabolism pathways (RPL10L, HMGCLL1, CIDEA, GNG10, HAPLN1, DIO3, OGN, CHST13) (Figure 5B). Mito-Tempo altered genes in Type II CD associated with metabolism of proteins (GALNT13, FAP, HIST1H2BI, GP2, IGF2, PROZ, GZMB, LYPD1, ESR1, GLIS1, HIST1H4C). Genes with obvious changes by Mito-Tempo in Type I or Type II patients (clusters A and D in Figure 5A; Table S5) were also analyzed for pathway enrichment. Genes in clusters A or D were associated with significantly upregulated signaling by $G$ protein-coupled receptors (GPCR) in Type I patients (OR52D1, RASGRF2, RGS17, ADCY4, AGTR1, RGS8, GNG10) and downregulated GPCR signaling in Type II patients (RASGRF2, RGS17, and ADCY4) (Figure 5C). 

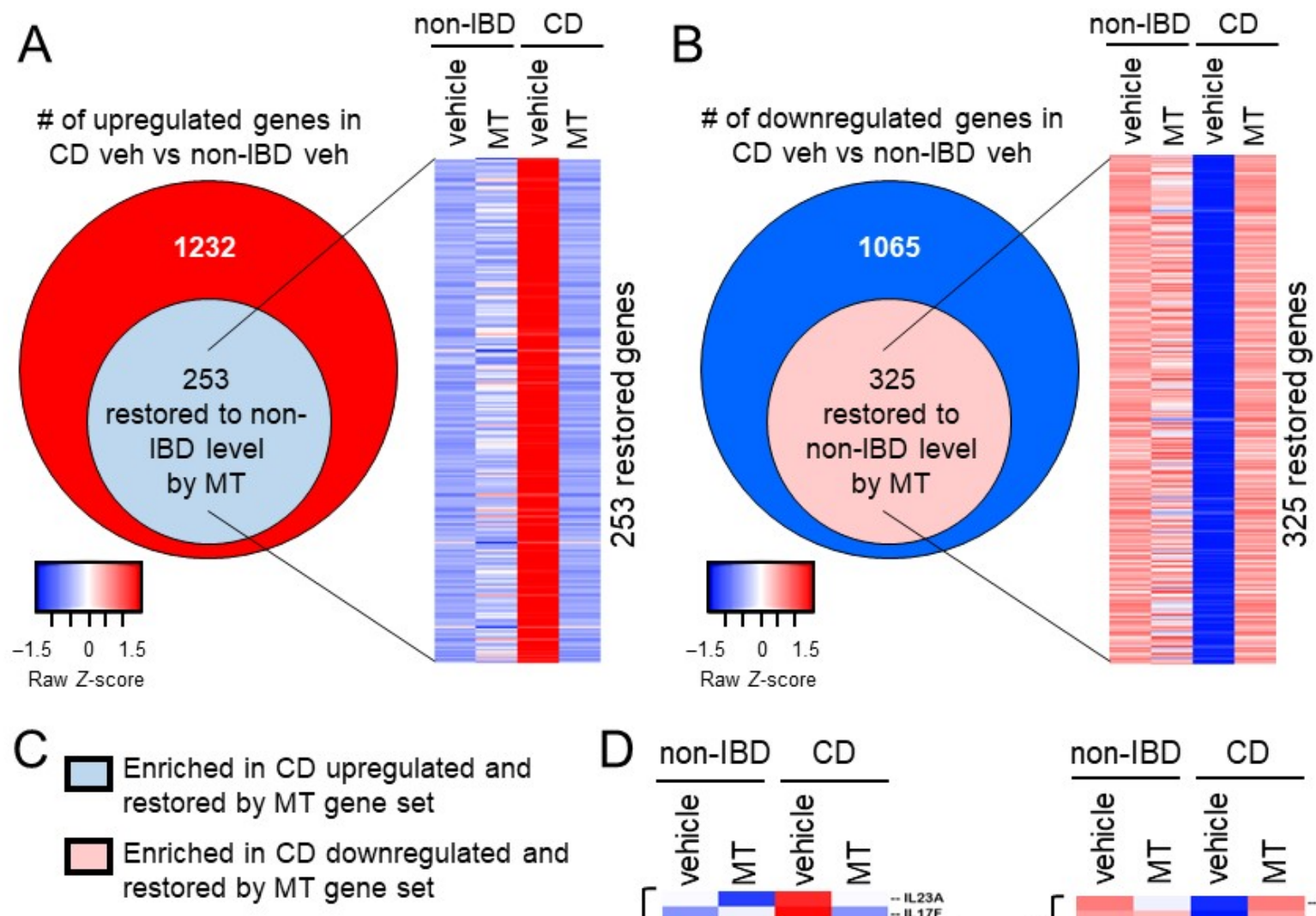

(n) number of significant pathways within this umbrella pathway
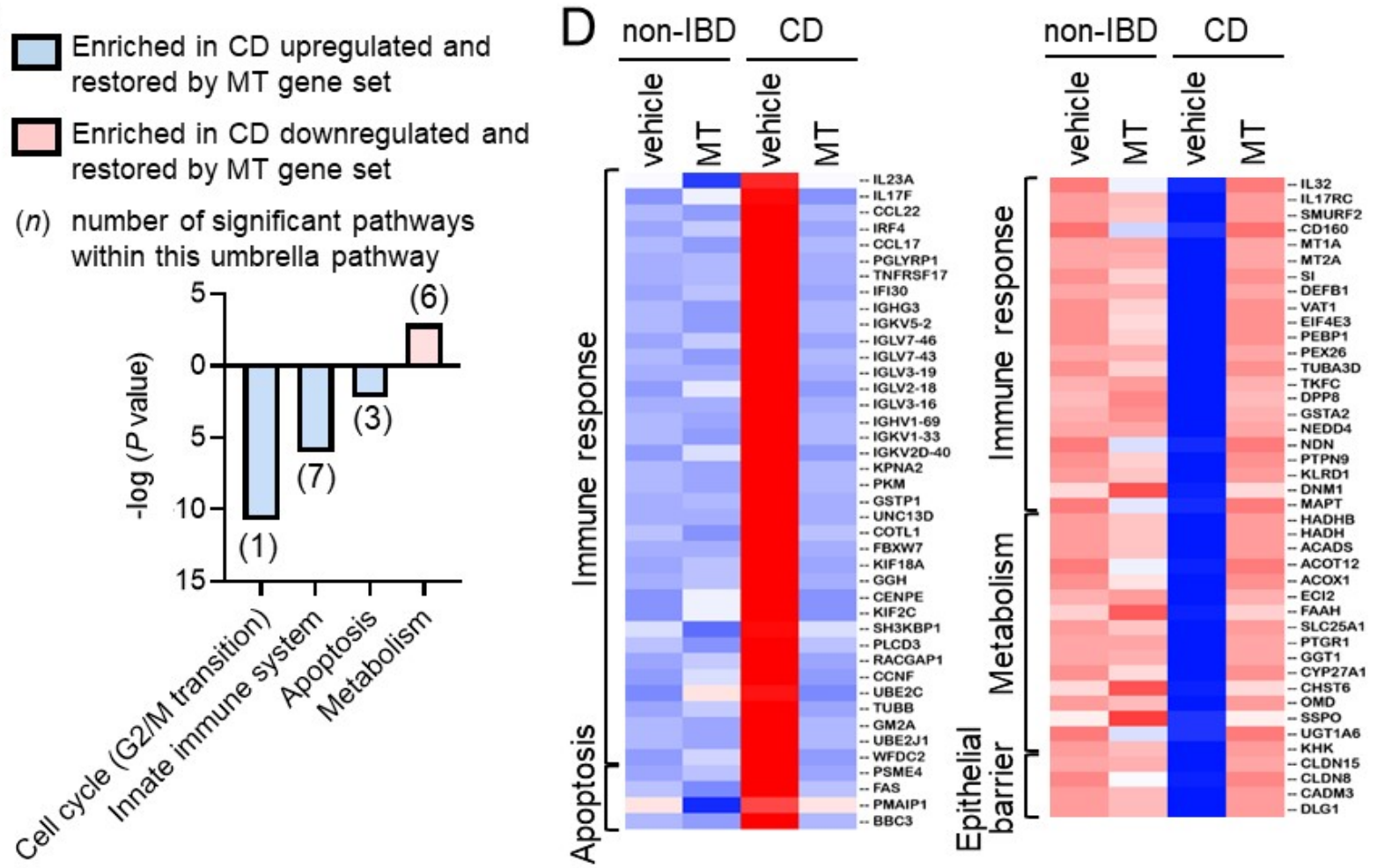

Figure 4. Mito-Tempo alters inflammatory response, metabolism, apoptotic, and epithelial barrier function gene signatures in CD patients. Ileal biopsies from CD and non-IBD patients were analyzed by RNA-seq after $2 \mathrm{~h}$ ex vivo incubation with Mito-Tempo or vehicle. (A,B) Diagrams summarizing the number of differentially expressed genes up- or down-regulated in CD and restored by Mito-Tempo treatment to non-IBD level. $p$ adj $<0.05$. (C) Significantly enriched pathways by Reactome analysis of DEGs in CD restored to non-IBD level by Mito-Tempo. (D) Heat maps of significantly upregulated or downregulated genes in CD restored to non-IBD expression by Mito-Tempo. $n=13$ veh non-IBD, 15 Mito-Tempo non-IBD, 13 veh active CD, 16 Mito-Tempo active CD. $p<0.05$ was considered significant in pathway selection. 


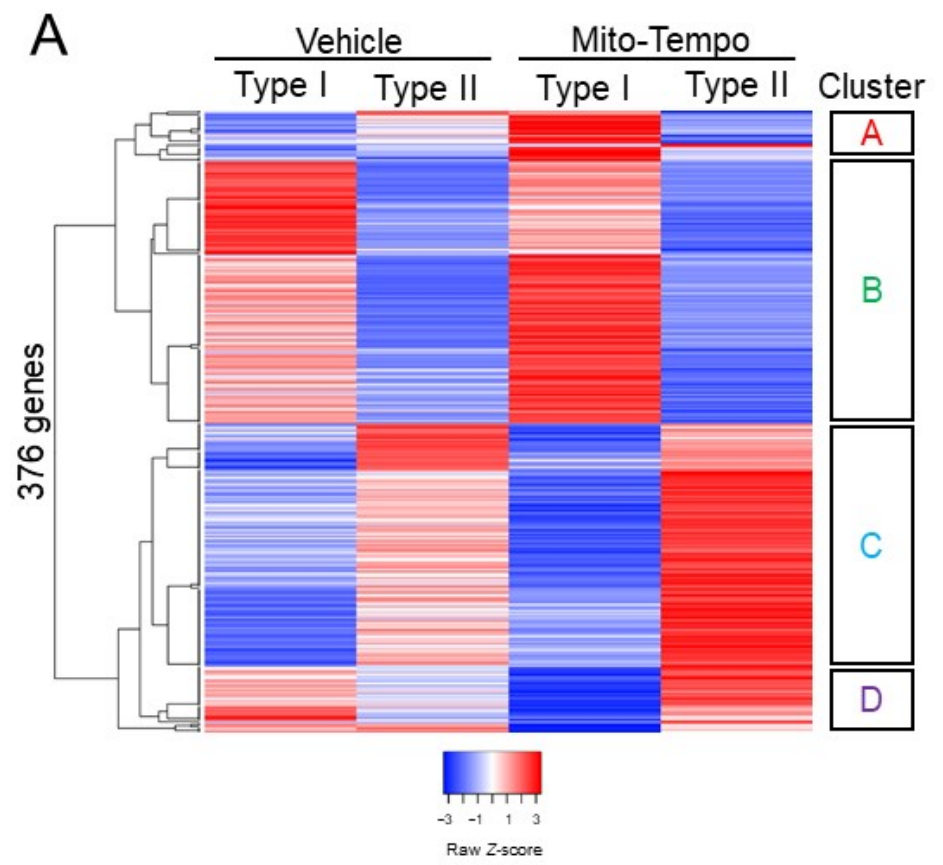
B $\square$ Enriched in downregulated by MT in Type I gene set
Enriched in upregulated by MT in Type I gene set
$\square$ Enriched in upregulated by MT in Type II gene set

(n) number of significant pathways within this umbrella pathway
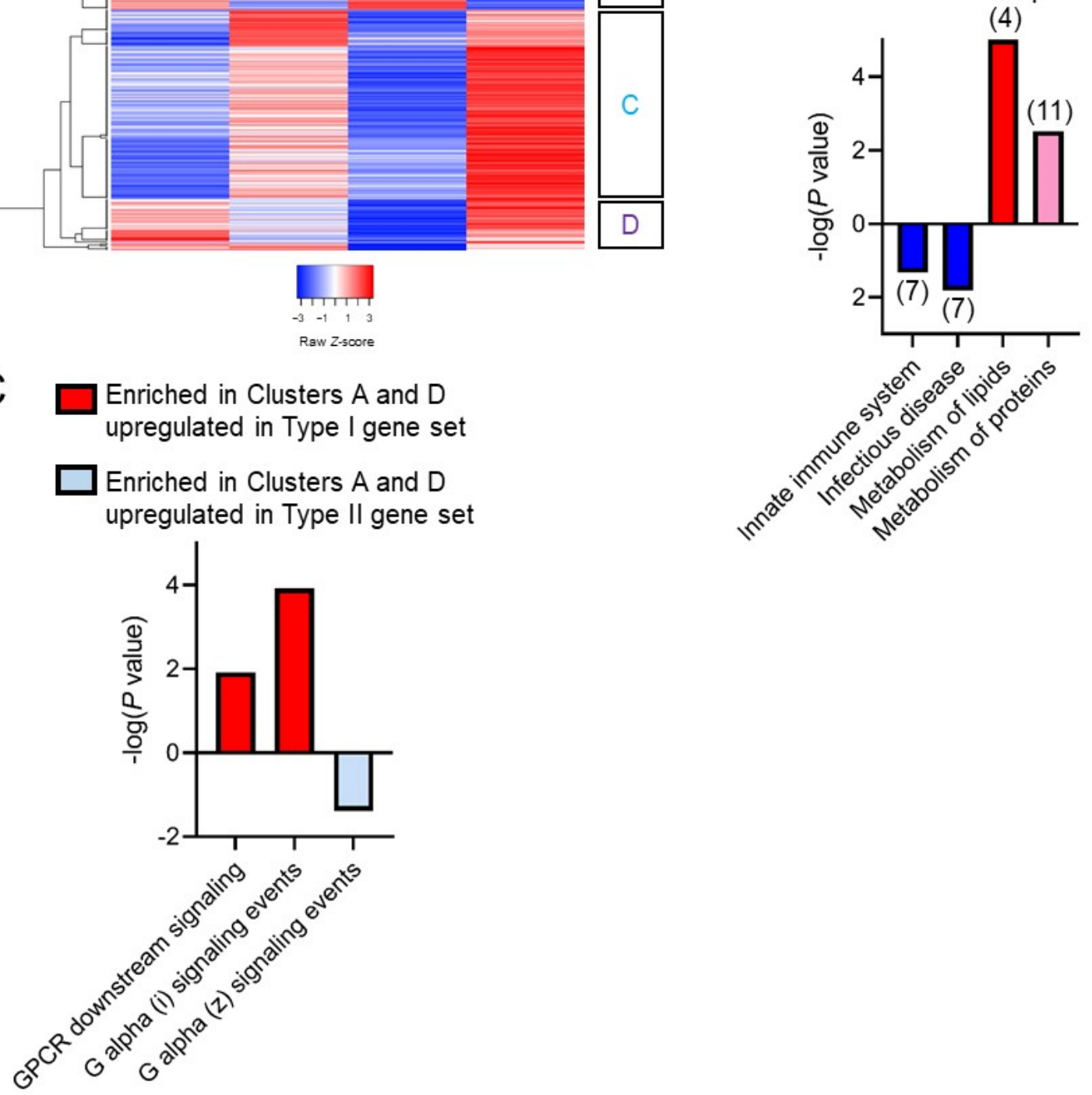

Figure 5. Paneth cell phenotype is associated with unique Mito-Tempo-induced gene signatures. (A) Heat maps based on hierarchical clustering of gene expression in Type I and Type II Paneth cell phenotype CD patients; (B) significantly enriched pathways by Reactome analysis of logFoldChange > 1.5 DEGs by Mito-Tempo in Type I or II patients; (C) significantly enriched pathways by Reactome analysis of genes in Clusters A and D shown in (A). $p<0.05$ was considered significant in pathway selection.

\section{Discussion}

Emerging studies linking mitochondrial health and IBD suggest the potential for mitochondrial-targeted interventions for ulcerative colitis and $\mathrm{CD}$. Here, our results demonstrate that during active $\mathrm{CD}$ inflammation, the epithelium exhibited severe mitochondrial damage evident in Paneth cells, goblet cells, and enterocytes. Independent of inflammation, CD Paneth cells, but not goblet cells or enterocytes, exhibited mitochondrial ultrastructural abnormalities with highest proportion in patients stratifying as the Type I phenotype. 
Targeting impaired mitochondria as an underlying contributor to inflammation provides a novel treatment approach for CD.

Multiple mitochondrial-targeted therapeutics have been tested in preclinical models of intestinal inflammation. The majority thus far have targeted the elimination of mtROS via antioxidant function since $\mathrm{mtROS}$ are elevated during impaired mitochondrial function, induce cellular damage, and act as stress signaling intermediates [33]. Synthetic mtROS scavengers (Mito-Tempo and MitoQ) have been shown to ameliorate intestinal inflammation in mice and enhance barrier function in CD patient colonic biopsies [9,34-36]. As an alternate to targeting $\mathrm{mtROS}$, a recent study demonstrated that altering mitochondrial metabolism to favor oxidative phosphorylation by treatment with dichloroacetate improved ISC function in organoids cultured from inflamed $\mathrm{TNF}^{\triangle \mathrm{ARE}}$ mice [20]. Additionally, preclinical models have shown protection against colitis by a key regulator of mitochondrial biogenesis, PGC1 $\alpha$ [37], but this has not been studied in CD or mouse models of ileitis. Our results demonstrate that PPARGC1A was upregulated in CD biopsies, which may represent an adaptive response to ongoing mitochondrial damage during $C D$ inflammation and deserves further study. By means of transcriptomics, we show that Mito-Tempo rapidly normalized the expression of $25 \%$ of altered CD genes to levels demonstrated in non-IBD patients. Reactome pathway analysis revealed that the Mito-Tempo-restored genes in CD patients included signatures associated with antigen processing, lipid metabolism, apoptosis, and IL-17/IL-23 signaling, all of which are relevant to CD pathology.

Numerous antigen processing genes were altered by Mito-Tempo in CD patients. Antigen processing is an important step prior to presentation by antigen presenting cells, which include dendritic cells, macrophages, B cells, and epithelial cells in the gut. It has been demonstrated that both $\mathrm{T}$ cells and dendritic cells exhibit increased intracellular ROS upon antigen-specific interaction and that alteration of oxidation state interferes with bidirectional dendritic cell/T cell communication [38,39]. Specifically, ROS has been shown to be important in effective antigen cross presentation by gut dendritic cells to elicit antigenspecific $T$ cell responses [40]. In terms of IBD, activated dendritic and T cells accumulate at sites of inflammation and targeting their activation provides a potential therapeutic target [41,42]. Our results suggest that Mito-Tempo-induced alteration of ROS influences antigen processing genes in CD patients. Further studies are needed to determine which antigen processing cell(s) are affected by ROS inhibition and how this relates to pathology in CD.

It is not surprising that lipid metabolism and apoptosis are altered by mitochondrial therapeutic targeting given that these pathways are associated with this organelle [11,33]. Redox status and the production of ROS are linked to energy metabolism, including lipid metabolism, with regulators of metabolic flux sensitive to oxidants [43]. Furthermore, during elevated ROS, lipids, especially polyunsaturated fatty acids, can be damaged by oxidants. This is called lipid peroxidation and has been shown to induce apoptosis [44]. In terms of apoptotic genes, Mito-Tempo was shown to alter gene expression of FAS, and BH3only proteins PMAIP1 (NOXA) and BBC3 (PUMA), all of which play a critical role in the induction of cell death, dependent on oxidative stress and other cell death signals [45-47].

The effect of Mito-Tempo on IL-17/IL-23 signaling suggests a novel mechanism whereby mtROS modulates CD inflammation via IL-17/IL-23, the targeting of which by mirikizumab or guselkumab was recently reported to have benefits in phase 2 clinical trials for CD [44,48]. The role of mitochondrial-derived ROS has been shown to be crucial for $\mathrm{CD}^{+} \mathrm{T}$ cell activation and differentiation $[49,50]$. However, the mechanism whereby mitochondrial-derived ROS exhibits this effect on T cells is not fully elucidated and could involve direct ROS signaling and/or ROS influence of the redox state of the cell. Mitochondrial-derived ROS-mediated activation of pathogenic Th17 cells producing IL-17 and IL-23 has not been previously studied in IBD patients. However, studies of CD4 ${ }^{+}$ $\mathrm{T}$ cells in rheumatoid arthritis patients demonstrated that differentiation to pathogenic Th17 cells was dependent on increased ROS production, which could be inhibited by Mito-Tempo [51]. Our results corroborate these findings with decreased IL23A, IL17F, IL32, 
and IL17RC expression in CD biopsies treated with Mito-Tempo. IL-17F and IL-17A are produced by type 3 innate immune cells (ILCs) and subsets of T cells including Th17 cells, $\mathrm{CD}^{+} \mathrm{T}$ cells, natural killer T cells, and $\gamma \delta \mathrm{T}$ cells [52]. IL-17F, but not IL-17A, is secreted by activated monocytes, basophils, mast cells, and gut epithelial cells and has greater affinity for IL-17RC, which is dominantly expressed in non-hematopoietic cells.

Whether Paneth cell defects in humans cause mitochondrial dysfunction or vice versa remains unknown. Our recent study in mice demonstrated that the induction of mitochondrial dysfunction by deletion of $P h b 1$ in intestinal epithelial cells triggered Paneth cell abnormalities and spontaneous ileitis in mice [9]. Paneth cell-specific deletion of Phb1 driven by Defa6-Cre or Mist1-CreER ${ }^{T 2}$ was sufficient to drive spontaneous ileitis, suggesting a causative role of mitochondrial dysfunction in ileitis that initiates in Paneth cells [9]. Additionally, induction of mitochondrial stress specifically in Lgr5+ ISC via Hsp60 deletion causes the development of abnormal Paneth cells [20]. These results suggest that mitochondrial health influences Paneth cell health. ISC niche abnormalities including Paneth cell defects were evident before severe inflammation in $\mathrm{TNF}^{\triangle \mathrm{ARE}}$ mice and in uninvolved tissue of CD patients [20]. This suggests that mitochondrial alterations likely comprise early molecular events before the onset of severe disease pathology and that Paneth cells are highly susceptible to mitochondrial dysfunction. Mitochondrial health may be especially important in Paneth cells since they are terminally differentiated, long-lived cells (30-60 days), in which damage mitochondria are not diluted by cell replication [2]. In comparison, enterocytes and goblet cells turnover every 3-5 days, thereby preventing the persistence of damaged mitochondria. Here, stratification of RNAseq results based on Paneth cell phenotyping revealed innate immune response, lipid and protein metabolism, and GPCR signaling as altered by Mito-Tempo in Type I CD patients. Mitochondrial signals are known activators of innate immune signaling including activation of the NLRP3 inflammasome [53]. The downregulation of SIGLEC14 by Mito-Tempo specifically in Type I CD patients implicates suppressed activation of inflammasome and macrophages [54]. Of note, impaired GPCR signaling is associated with IBD [55]. GPCR signaling was recently shown to be necessary for Paneth cell maturation and mucosal healing, with the absence of $\mathrm{G} \alpha_{\mathrm{q}} / \mathrm{G} \alpha_{11}$-coupled receptors inducing differentiation of Paneth cells toward goblet cells [56].

Previous studies indicate that Paneth cell defects result from integration of susceptibility gene(s) interaction with environmental triggers [57]. Indeed, a complex interaction of genes, microbiota, and Paneth cell functions are evident given that the Type I Paneth cell phenotype in non-IBD subjects does not correlate with altered mucosal mitochondrial genes or altered gut microbiome [6]. The mechanisms whereby non-IBD patients develop the Type I Paneth cell phenotype are not fully understood. Although the cohort of patients we studied was adult, previous studies demonstrated that both pediatric and adult non-IBD patients exhibit the Type I Paneth cell phenotype [6]. Environmental factors could lead to Paneth cell defects, such as viral infection, which has been shown to cause Paneth cell defects in genetically susceptible mice [18]. Additionally, longitudinal studies are needed to follow these non-IBD patients with the Type I Paneth cell phenotype to determine whether these patients develop IBD, and if so, this would suggest Paneth cell defects might serve as a cellular biomarker for the risk of developing disease [6]. ATG16L1 T300A, NOD2, and LRRK2 risk alleles were associated with the Type I Paneth cell phenotype in adult CD cohorts depending on ethnic background $[3,4,7]$. In our cohort of CD patients, the ATG16L1 T300A risk allele was associated with abnormal Paneth cells. The T300A polymorphism has been shown to reduce autophagy in multiple cell types [57]. In Paneth cells, autophagy has been shown to be important for antimicrobial peptide secretion via secretory autophagy, defense against invading microbes, and resolving ER stress [58]. The present data implicate a role of autophagy in the maintenance of a healthy mitochondrial pool (mitophagy) in Paneth cells. Although mitochondrial health was not reported in all mouse models deficient in autophagy genes resulting in Paneth cell defects, Atg $1611^{\mathrm{T} 300 \mathrm{~A}}$ and $A \operatorname{tg} 16 l^{H M}$ mice exhibited Paneth cells with degenerating mitochondria [19,59]. Further 
studies are necessary to determine whether $C D$ susceptibility genes involved in autophagy result in a damaged mitochondrial pool in Paneth cells and the specific role of mitophagy in $\mathrm{CD}$ pathogenesis.

The limitations of the present study include the low number of patients recruited into analysis after excluding biopsy samples that had an inadequate number of crypts for Paneth cell phenotyping. Similar exclusion of numerous patients was noted in previous studies using endoscopy biopsies for Paneth cell phenotyping [6]. We focused our patient cohort on adult $C D$ patients, but given that pediatric patients exhibit higher prevalence of Paneth cell defects compared to adults [6], further studies are needed to determine whether CD pediatric patients may especially benefit from mitochondrial-targeted therapy. Although we chose RNA-seq to gain insight into global mucosal pathways altered by a mitochondrial-targeted therapeutic (Mito-Tempo), RNA-seq analysis does not provide transcriptomic analysis for individual cell types present in ileal mucosal biopsies (epithelial cells, immune cells, and fibroblasts/myofibroblasts). To overcome this heterogeneous transcriptomics, single-cell RNA sequencing will be performed in future studies to access alterations within specific epithelial types, such as Paneth cells, with both Type I and Type II Paneth cell phenotype patients included. Our study is limited by the unknown uptake, distribution, and activity of Mito-Tempo within heterogeneous biopsy samples. To gain insight into mitochondrial biogenesis and dynamics during $C D$, markers in addition to PPARGC1A gene expression should be measured, including mitochondrial DNA level and expression of key fission (DRP1, FIS1) and fusion (MFN1/2, OPA1) proteins. Lastly, intestinal biopsies provide a limited snapshot of intestinal physiology. Longitudinal studies will need to be performed to determine whether mitochondrial dysfunction is altered over the course of $C D$.

These results identify CD enterocytes, goblet cells, and Paneth cells as being susceptible to mitochondrial dysfunction during active inflammation. Type I CD patients with Paneth cell defects are susceptible to mitochondrial dysfunction independent of active inflammation. Protective gene signatures are induced by Mito-Tempo in active CD biopsies. Mitochondrial-targeted therapies may improve outcomes in ileal CD patients and may provide adjuvant therapy for Type I patients to extend remission.

Supplementary Materials: The following are available online at https:/ / www.mdpi.com/article/10 .3390 / cells10061349/s1, Figure S1: Significantly enriched gene signatures in CD vs. non-IBD patients by Reactome analysis; Figure S2: RNA expression of several transcripts in human ileal mucosal biopsies by quantitative real time-PCR; Table S2: The 253 of the 1232 upregulated genes in CD patients restored to non-IBD expression level by Mito-Tempo; Table S3: The 325 of the 1065 downregulated genes in CD patients restored to non-IBD gene expression level by Mito-Tempo; Table S4: The 376 altered genes with significant $p$ value; and Table S5: Genes present in Figure 5A Clusters A and D.

Author Contributions: Study concept and design: L.A.F., A.L.T. Data acquisition: K.M.A., D.N.J., A.D.S., D.S.K., K.T., E.O., T.D., L.A.F., A.L.T. Data analysis and interpretation: K.M.A., B.A.K., K.V., L.A.F., A.L.T. Drafting the manuscript: K.M.A. Critical revision of the manuscript for important intellectual content: B.A.K., L.A.F., A.L.T. All authors have read and agreed to the published version of the manuscript.

Funding: This work was supported by National Institutes of Health grants R01-DK117001 (ALT), Litwin IBD Pioneers Crohn's Colitis Foundation 301869 (ALT), and GI and Liver Innate Immune Program (GALIIP)—University of Colorado Anschutz (ALT).

Institutional Review Board Statement: The Baylor University Medical Center (protocol 016-083) and Dallas Veterans Affairs Medical Center (protocol 12-053) institutional review boards approved this study. Written informed consent was received from all participants prior to inclusion in the study.

Informed Consent Statement: All patients recruited for this study provided informed consent.

Data Availability Statement: The high-throughput sequencing data from Novogene for this study have been submitted to the NCBI Sequence Read Archive (SRA) under accession number GSE159751. 
Acknowledgments: We thank Ricardo Olivarez and Stephanie Kara at the Anatomic Pathology Laboratory at Children's Health Medical Center Dallas, TX for assistance with electron microscopy. We thank an Cartwright at the Division of Gastroenterology and Hepatology, University of Colorado School of Medicine, Aurora, CO for assistance with large data set handling. This work was supported by National Institutes of Health grants R01-DK117001 (ALT), Litwin IBD Pioneers Crohn's Colitis Foundation 301869 (ALT), and GI and Liver Innate Immune Program (GALIIP)—University of Colorado Anschutz (ALT).

Conflicts of Interest: The authors declare no conflict of interest, financial or otherwise.

\section{References}

1. Gajendran, M.; Loganathan, P.; Catinella, A.P.; Hashash, J.G. A comprehensive review and update on Crohn's disease. Dis. Mon. 2018, 64, 20-57. [CrossRef]

2. Clevers, H.C.; Bevins, C.L. Paneth cells: Maestros of the small intestinal crypts. Annu. Rev. Physiol. 2013, 75, 289-311. [CrossRef]

3. VanDussen, K.L.; Liu, T.C.; Li, D.; Towfic, F.; Modiano, N.; Winter, R.; Haritunians, T.; Taylor, K.D.; Dhall, D.; Targan, S.R.; et al. Genetic variants synthesize to produce paneth cell phenotypes that define subtypes of Crohn's disease. Gastroenterology 2014, 146, 200-209. [CrossRef] [PubMed]

4. Cadwell, K.; Liu, J.Y.; Brown, S.L.; Miyoshi, H.; Loh, J.; Lennerz, J.K.; Kishi, C.; Kc, W.; Carrero, J.A.; Hunt, S.; et al. A key role for autophagy and the autophagy gene Atg1611 in mouse and human intestinal Paneth cells. Nature 2008, 456, 259-263. [CrossRef]

5. Liu, T.C.; Gao, F.; McGovern, D.P.; Stappenbeck, T.S. Spatial and temporal stability of paneth cell phenotypes in Crohn's disease: Implications for prognostic cellular biomarker development. Inflamm. Bowel Dis. 2014, 20, 646-651. [CrossRef]

6. Liu, T.C.; Gurram, B.; Baldridge, M.T.; Head, R.; Lam, V.; Luo, C.; Cao, Y.; Simpson, P.; Hayward, M.; Holtz, M.L.; et al. Paneth cell defects in Crohn's disease patients promote dysbiosis. JCI Insight 2016, 1, e86907. [CrossRef] [PubMed]

7. Liu, T.C.; Naito, T.; Liu, Z.; VanDussen, K.L.; Haritunians, T.; Li, D.; Endo, K.; Kawai, Y.; Nagasaki, M.; Kinouchi, Y.; et al. LRRK2 but not ATG16L1 is associated with Paneth cell defect in Japanese Crohn's disease patients. JCI Insight 2017, 2, e91917. [CrossRef]

8. Stappenbeck, T.S.; McGovern, D.P.B. Paneth Cell Alterations in the Development and Phenotype of Crohn's Disease. Gastroenterology 2017, 152, 322-326. [CrossRef]

9. Jackson, D.N.; Panopoulos, M.; Neumann, W.L.; Turner, K.; Cantarel, B.L.; Thompson-Snipes, L.; Dassopoulos, T.; Feagins, L.A.; Souza, R.F.; Mills, J.C.; et al. Mitochondrial dysfunction during loss of prohibitin 1 triggers Paneth cell defects and ileitis. Gut 2020, 69, 1928-1938. [CrossRef]

10. Jackson, D.N.; Theiss, A.L. Gut bacteria signaling to mitochondria in intestinal inflammation and cancer. Gut Microbes 2020, 11, 285-304. [CrossRef] [PubMed]

11. Rath, E.; Moschetta, A.; Haller, D. Mitochondrial function-gatekeeper of intestinal epithelial cell homeostasis. Nat. Rev. Gastroenterol. Hepatol. 2018, 15, 497-516. [CrossRef]

12. Haberman, Y.; Karns, R.; Dexheimer, P.J.; Schirmer, M.; Somekh, J.; Jurickova, I.; Braun, T.; Novak, E.; Bauman, L.; Collins, M.H.; et al. Ulcerative colitis mucosal transcriptomes reveal mitochondriopathy and personalized mechanisms underlying disease severity and treatment response. Nat. Commun. 2019, 10, 38. [CrossRef]

13. Kugathasan, S.; Denson, L.A.; Walters, T.D.; Kim, M.O.; Marigorta, U.M.; Schirmer, M.; Mondal, K.; Liu, C.; Griffiths, A.; Noe, J.D.; et al. Prediction of complicated disease course for children newly diagnosed with Crohn's disease: A multicentre inception cohort study. Lancet 2017, 389, 1710-1718. [CrossRef]

14. Boyapati, R.K.; Dorward, D.A.; Tamborska, A.; Kalla, R.; Ventham, N.T.; Doherty, M.K.; Whitfield, P.D.; Gray, M.; Loane, J.; Rossi, A.G.; et al. Mitochondrial DNA Is a Pro-Inflammatory Damage-Associated Molecular Pattern Released During Active IBD. Inflamm. Bowel Dis. 2018, 24, 2113-2122. [CrossRef]

15. Rath, E.; Haller, D. Mitochondria at the interface between danger signaling and metabolism: Role of unfolded protein responses in chronic inflammation. Inflamm. Bowel Dis. 2012, 18, 1364-1377. [CrossRef]

16. Ho, G.T.; Aird, R.E.; Liu, B.; Boyapati, R.K.; Kennedy, N.A.; Dorward, D.A.; Noble, C.L.; Shimizu, T.; Carter, R.N.; Chew, E.T.S.; et al. MDR1 deficiency impairs mitochondrial homeostasis and promotes intestinal inflammation. Mucosal Immunol. 2018, 11, 120-130. [CrossRef] [PubMed]

17. Daperno, M.; D’Haens, G.; Van Assche, G.; Baert, F.; Bulois, P.; Maunoury, V.; Sostegni, R.; Rocca, R.; Pera, A.; Gevers, A.; et al. Development and validation of a new, simplified endoscopic activity score for Crohn's disease: The SES-CD. Gastrointest Endosc. 2004, 60, 505-512. [CrossRef]

18. Cadwell, K.; Patel, K.K.; Maloney, N.S.; Liu, T.C.; Ng, A.C.; Storer, C.E.; Head, R.D.; Xavier, R.; Stappenbeck, T.S.; Virgin, H.W. Virus-plus-susceptibility gene interaction determines Crohn's disease gene Atg16L1 phenotypes in intestine. Cell 2010, 141, 1135-1145. [CrossRef]

19. Liu, T.C.; Kern, J.T.; VanDussen, K.L.; Xiong, S.; Kaiko, G.E.; Wilen, C.B.; Rajala, M.W.; Caruso, R.; Holtzman, M.J.; Gao, F.; et al. Interaction between smoking and ATG16L1T300A triggers Paneth cell defects in Crohn's disease. J. Clin. Investig. 2018, 128, 5110-5122. [CrossRef] 
20. Khaloian, S.; Rath, E.; Hammoudi, N.; Gleisinger, E.; Blutke, A.; Giesbertz, P.; Berger, E.; Metwaly, A.; Waldschmitt, N.; Allez, M.; et al. Mitochondrial impairment drives intestinal stem cell transition into dysfunctional Paneth cells predicting Crohn's disease recurrence. Gut 2020. [CrossRef] [PubMed]

21. Murphy, M.P. How mitochondria produce reactive oxygen species. Biochem. J. 2009, 417, 1-13. [CrossRef]

22. Dikalova, A.E.; Bikineyeva, A.T.; Budzyn, K.; Nazarewicz, R.R.; McCann, L.; Lewis, W.; Harrison, D.G.; Dikalov, S.I. Therapeutic targeting of mitochondrial superoxide in hypertension. Circ. Res. 2010, 107, 106-116. [CrossRef]

23. Fuller, M.K.; Faulk, D.M.; Sundaram, N.; Mahe, M.M.; Stout, K.M.; von Furstenberg, R.J.; Smith, B.J.; McNaughton, K.K.; Shroyer, N.F.; Helmrath, M.A.; et al. Intestinal stem cells remain viable after prolonged tissue storage. Cell Tissue Res. 2013, 354, 441-450. [CrossRef]

24. Heiseke, A.F.; Faul, A.C.; Lehr, H.A.; Forster, I.; Schmid, R.M.; Krug, A.B.; Reindl, W. CCL17 promotes intestinal inflammation in mice and counteracts regulatory T cell-mediated protection from colitis. Gastroenterology 2012, 142, 335-345. [CrossRef]

25. Dornhoff, H.; Becker, C.; Wirtz, S.; Strand, D.; Tenzer, S.; Rosfa, S.; Neufert, C.; Mudter, J.; Markl, J.; Siebler, J.; et al. A variant of Smurf2 protects mice against colitis-associated colon cancer by inducing transforming growth factor beta signaling. Gastroenterology 2012, 142, 1183-1194.e4. [CrossRef] [PubMed]

26. Seo, G.-Y.; Shui, J.-R.; Mikulski, R.; Wang, Q.; Takahashi, D.; Giles, D.A.; Iwaya, H.; Sethi, A.; Kim, P.-H.; Cheroutre, H.; et al. CD160-HVEM signaling in intestinal epithelial cells modulates gut microbial homeostasis. J. Immunol 2019, $202,191.11$.

27. Stange, E.F.; Schroeder, B.O. Microbiota and mucosal defense in IBD: An update. Expert Rev. Gastroenterol. Hepatol. 2019, 13, 963-976. [CrossRef] [PubMed]

28. Waeytens, A.; De Vos, M.; Laukens, D. Evidence for a potential role of metallothioneins in inflammatory bowel diseases. Mediators Inflamm. 2009, 2009, 729172. [CrossRef] [PubMed]

29. Cui, H.; Shu-Hong, Y.; Qiao, M. Expression of DLG1 and DLG5 in the Intestinal Epithelium of Patients with CD. Inflamm. Bowel Dis 2016, 22, E43-E44. [CrossRef] [PubMed]

30. Darsigny, M.; Babeu, J.P.; Dupuis, A.A.; Furth, E.E.; Seidman, E.G.; Levy, E.; Verdu, E.F.; Gendron, F.P.; Boudreau, F. Loss of hepatocyte-nuclear-factor-4alpha affects colonic ion transport and causes chronic inflammation resembling inflammatory bowel disease in mice. PLoS ONE 2009, 4, e7609. [CrossRef] [PubMed]

31. Zeissig, S.; Burgel, N.; Gunzel, D.; Richter, J.; Mankertz, J.; Wahnschaffe, U.; Kroesen, A.J.; Zeitz, M.; Fromm, M.; Schulzke, J.D. Changes in expression and distribution of claudin 2, 5 and 8 lead to discontinuous tight junctions and barrier dysfunction in active Crohn's disease. Gut 2007, 56, 61-72. [CrossRef] [PubMed]

32. Uchiyama, K.; Kishi, H.; Komatsu, W.; Nagao, M.; Ohhira, S.; Kobashi, G. Lipid and Bile Acid Dysmetabolism in Crohn's Disease. J. Immunol. Res. 2018, 2018, 7270486. [CrossRef]

33. Shadel, G.S.; Horvath, T.L. Mitochondrial ROS signaling in organismal homeostasis. Cell 2015, 163, 560-569. [CrossRef]

34. Chu, F.F.; Esworthy, R.S.; Doroshow, J.H.; Grasberger, H.; Donko, A.; Leto, T.L.; Gao, Q.; Shen, B. Deficiency in Duox2 activity alleviates ileitis in GPx1- and GPx2-knockout mice without affecting apoptosis incidence in the crypt epithelium. Redox Biol. 2017, 11, 144-156. [CrossRef]

35. Dashdorj, A.; Jyothi, K.R.; Lim, S.; Jo, A.; Nguyen, M.N.; Ha, J.; Yoon, K.S.; Kim, H.J.; Park, J.H.; Murphy, M.P.; et al. Mitochondriatargeted antioxidant MitoQ ameliorates experimental mouse colitis by suppressing NLRP3 inflammasome-mediated inflammatory cytokines. BMC Med. 2013, 11, 178. [CrossRef]

36. Wang, A.; Keita, A.V.; Phan, V.; McKay, C.M.; Schoultz, I.; Lee, J.; Murphy, M.P.; Fernando, M.; Ronaghan, N.; Balce, D.; et al. Targeting mitochondria-derived reactive oxygen species to reduce epithelial barrier dysfunction and colitis. Am. J. Pathol. 2014, 184, 2516-2527. [CrossRef] [PubMed]

37. Cunningham, K.E.; Vincent, G.; Sodhi, C.P.; Novak, E.A.; Ranganathan, S.; Egan, C.E.; Stolz, D.B.; Rogers, M.B.; Firek, B.; Morowitz, M.J.; et al. Peroxisome Proliferator-activated Receptor-gamma Coactivator 1-alpha (PGC1alpha) Protects against Experimental Murine Colitis. J. Biol. Chem. 2016, 291, 10184-10200. [CrossRef]

38. Matsue, H.; Edelbaum, D.; Shalhevet, D.; Mizumoto, N.; Yang, C.; Mummert, M.E.; Oeda, J.; Masayasu, H.; Takashima, A. Generation and function of reactive oxygen species in dendritic cells during antigen presentation. J. Immunol. 2003, 171, 3010-3018. [CrossRef]

39. Kotsias, F.; Hoffmann, E.; Amigorena, S.; Savina, A. Reactive oxygen species production in the phagosome: Impact on antigen presentation in dendritic cells. Antioxid Redox Signal 2013, 18, 714-729. [CrossRef]

40. Kim, S.H.; Cho, B.H.; Kim, K.S.; Jang, Y.S. Complement C5a promotes antigen cross-presentation by Peyer's patch monocytederived dendritic cells and drives a protective CD8(+) T cell response. Cell Rep. 2021, 35, 108995. [CrossRef] [PubMed]

41. Bates, J.; Diehl, L. Dendritic cells in IBD pathogenesis: An area of therapeutic opportunity? J. Pathol. 2014, 232, 112-120. [CrossRef]

42. Giuffrida, P.; Di Sabatino, A. Targeting T cells in inflammatory bowel disease. Pharmacol. Res. 2020, 159, 105040. [CrossRef]

43. Quijano, C.; Trujillo, M.; Castro, L.; Trostchansky, A. Interplay between oxidant species and energy metabolism. Redox Biol. 2016, 8, 28-42. [CrossRef] 
44. A SPECIAL MEETING REVIEW EDITION: Highlights in Inflammatory Bowel Disease From the 14th Congress of ECCO: A Review of Selected Presentations From the 14th Congress of the European Crohn's and Colitis Organisation (ECCO) March 6-9, 2019 Copenhagen, Denmark Special Reporting on: VARSITY: A Double-Blind, Double-Dummy, Randomized Controlled Trial of Vedolizumab Versus Adalimumab in Patients With Active Ulcerative Colitis Analyses of Data From the VISIBLE 1 and 2 Trials: Vedolizumab in Patients With Ulcerative Colitis or Crohn's Disease Improved Endoscopic Outcomes and Mucosal Healing of Upadacitinib as an Induction Therapy in Adults With Moderately to Severely Active Ulcerative Colitis: Data From the U-ACHIEVE Study Long-Term Safety of Vedolizumab in Ulcerative Colitis and Crohn's Disease: Final Results From the GEMINI LTS Study Pediatric Crohn's Disease Adalimumab Level-Based Optimization Treatment (PAILOT) Randomized Controlled Trial Maintenance Treatment With Mirikizumab, a P19-Directed IL-23 Antibody: 52-Week Results in Patients With Moderately to Severely Active Ulcerative Colitis Real-World Effectiveness and Safety of Vedolizumab and Anti-TNF Therapy in Biologic-Naive Patients With Ulcerative Colitis or Crohn's Disease: Results From the EVOLVE Study A Randomized, Multicenter, Double-Blind, Placebo-Controlled Study of a Targeted-Release Oral Cyclosporine Formulation in the Treatment of Mild to Moderate Ulcerative Colitis: Efficacy Results Real-World Analyses of Patients With IBD Treated With Vedolizumab PLUS Meeting Abstract Summaries With Expert Commentary by: Edward V. Loftus Jr, MD Professor of MedicineDivision of Gastroenterology and HepatologyMayo ClinicRochester, Minnesota. Gastroenterol. Hepatol. 2019, 15, 1-24.

45. Medan, D.; Wang, L.; Toledo, D.; Lu, B.; Stehlik, C.; Jiang, B.H.; Shi, X.; Rojanasakul, Y. Regulation of Fas (CD95)-induced apoptotic and necrotic cell death by reactive oxygen species in macrophages. J. Cell Physiol. 2005, 203, 78-84. [CrossRef]

46. Guikema, J.E.; Amiot, M.; Eldering, E. Exploiting the pro-apoptotic function of NOXA as a therapeutic modality in cancer. Expert Opin. Ther. Targets 2017, 21,767-779. [CrossRef] [PubMed]

47. Krishna, S.; Low, I.C.; Pervaiz, S. Regulation of mitochondrial metabolism: Yet another facet in the biology of the oncoprotein Bcl-2. Biochem. J. 2011, 435, 545-551. [CrossRef]

48. Macaluso, F.S.; Orlando, A.; Cottone, M. Anti-interleukin-12 and anti-interleukin-23 agents in Crohn's disease. Expert Opin. Biol. Ther. 2019, 19, 89-98. [CrossRef] [PubMed]

49. Sena, L.A.; Li, S.; Jairaman, A.; Prakriya, M.; Ezponda, T.; Hildeman, D.A.; Wang, C.R.; Schumacker, P.T.; Licht, J.D.; Perlman, $\mathrm{H}$; et al. Mitochondria are required for antigen-specific $\mathrm{T}$ cell activation through reactive oxygen species signaling. Immunity 2013, 38, 225-236. [CrossRef]

50. Mak, T.W.; Grusdat, M.; Duncan, G.S.; Dostert, C.; Nonnenmacher, Y.; Cox, M.; Binsfeld, C.; Hao, Z.; Brustle, A.; Itsumi, M.; et al. Glutathione Primes T Cell Metabolism for Inflammation. Immunity 2017, 46, 1089-1090. [CrossRef]

51. Zhao, C.; Gu, Y.; Zeng, X.; Wang, J. NLRP3 inflammasome regulates Th17 differentiation in rheumatoid arthritis. Clin. Immunol. 2018, 197, 154-160. [CrossRef]

52. McGeachy, M.J.; Cua, D.J.; Gaffen, S.L. The IL-17 Family of Cytokines in Health and Disease. Immunity 2019, 50, 892-906. [CrossRef]

53. Prochnicki, T.; Latz, E. Inflammasomes on the Crossroads of Innate Immune Recognition and Metabolic Control. Cell Metab. 2017, 26, 71-93. [CrossRef] [PubMed]

54. Tsai, C.M.; Riestra, A.M.; Ali, S.R.; Fong, J.J.; Liu, J.Z.; Hughes, G.; Varki, A.; Nizet, V. Siglec-14 Enhances NLRP3-Inflammasome Activation in Macrophages. J. Innate Immun. 2020, 12, 333-343. [CrossRef]

55. Melhem, H.; Kaya, B.; Ayata, C.K.; Hruz, P.; Niess, J.H. Metabolite-Sensing G Protein-Coupled Receptors Connect the DietMicrobiota-Metabolites Axis to Inflammatory Bowel Disease. Cells 2019, 8, 450. [CrossRef]

56. Mashima, H.; Watanabe, N.; Sekine, M.; Matsumoto, S.; Asano, T.; Yuhashi, K.; Sagihara, N.; Urayoshi, S.; Uehara, T.; Fujiwara, J.; et al. The role of Galphaq/Galpha11 signaling in intestinal epithelial cells. Biochem. Biophys. Rep. 2018, 13, 93-98. [CrossRef]

57. Lassen, K.G.; Kuballa, P.; Conway, K.L.; Patel, K.K.; Becker, C.E.; Peloquin, J.M.; Villablanca, E.J.; Norman, J.M.; Liu, T.C.; Heath, R.J.; et al. Atg16L1 T300A variant decreases selective autophagy resulting in altered cytokine signaling and decreased antibacterial defense. Proc. Natl. Acad. Sci. USA 2014, 111, 7741-7746. [CrossRef]

58. Kim, S.; Eun, H.S.; Jo, E.K. Roles of Autophagy-Related Genes in the Pathogenesis of Inflammatory Bowel Disease. Cells 2019, 8, 77. [CrossRef] [PubMed]

59. Cadwell, K.; Patel, K.K.; Komatsu, M.; Virgin, H.W.t.; Stappenbeck, T.S. A common role for Atg16L1, Atg5 and Atg7 in small intestinal Paneth cells and Crohn disease. Autophagy 2009, 5, 250-252. [CrossRef] [PubMed] 